\title{
Foraging behaviour and prey size spectra of larval herring Clupea harengus
}

\author{
Peter Munk
}

Danish Institute for Fisheries and Marine Research, Charlottenlund Castle, DK-2920 Charlottenlund, Denmark

\begin{abstract}
When fish increase in size, the size spectrum of ingested prey increases. This observation has led to the impression that the available food resource increases as fish grow. However, it has been proposed that the size spectrum of prey remains the same on a relative scale and, accordingly, that the available biomass of food as a proportion of the predator biomass will not increase. In order to assess the uniformity of relative prey size spectra of herring larvae and their background in larval foraging behaviour, a set of experimental and field investigations has been carried out. In the experiments, 4 size groups of larval herring Clupea harengus L. were studied when preying on 6 size groups of copepods. Larval swimming and attack behaviour changed with prey size and were related to the ratio between prey length and larval length. The effective search rate showed a maximum when prey length was about 0.027 of larval length. In the field investigations, the relative prey size spectra of 6 size groups of larvae were described. The widths of these spectra were not significantly different and they all attained maxima when the relative length of prey was about 0.028 of larval length. Thus, larval foraging was, to a large extent, determined by the relative size of prey, with significant selection for the preferred sizes. Results imply that only a restricted part of the potential prey (sizes) is of value in larval foraging and consumption and that coincidence between prey size spectra and peaks in the biomass spectra of the environment is important to larval growth and survival.
\end{abstract}

\section{INTRODUCTION}

Ecological studies on larval fish have shown that growth of larvae varies significantly both temporally and spatially (e.g. Jones 1985, Suthers et al. 1989, Munk et al. 1991). In order to assess the correspondence between observed growth and abundance of prey, the density of zooplankton is often determined simultaneously with the sampling of fish larvae. However, only a part of the size spectrum of zooplankters is available to the fish larvae, and inappropriate comparison between irrelevant size ranges of zooplankton and larvae has, in a number of cases, led to misinterpretation of the relative distributions of larvae and their prey (Frank 1988). Actual availability of prey has to be considered, using information about the prey field of the larvae concerned.

The prey field of larvae is determined by active and passive elements of their foraging. A number of models explaining the general processes in the prey-predator relationship have been proposed. Among the most debated models are the Reactive Field Volume Model (RFVM), the Apparent Size Model (ASM) and the Optimal Diet Model (ODM). According to the RFVM, the fish take each prey as encountered and, because larger prey are sighted at greater distances, they will be taken more frequently than the smaller prey (Ware 1972). The ASM, proposed by O'Brien et al. (1976), hypothesizes that the prey that appears largest in the visual field is selected, whereas according to the ODM fish actively select the prey most profitable in net energy gain (Schoener 1971, Pyke et al. 1977).

In a number of studies, these theories have been tested and compared (e.g. Wetterer \& Bishop 1985, Bence \& Murdoch 1986) but no firm conclusion about general processes has yet been reached. It has become clear, however, that selection cannot be described by the RFVM alone. On the other hand, this theory, because of its simplicity, is well suited as a baseline against which observed preferences can be evaluated.

Observations of prey preference under natural conditions are mainly based on analyses of gut contents. 
Relative amounts of different prey sizes and types in the gut are determined. The prey field has then often been described by the range of prey sizes in the gut (e.g. Cohen \& Lough 1983). However, range is a poor measure statistically, because of its dependence on sample sizes, and other problems arise when viewing prey size differences on absolute scales only. It is more appropriate to describe the prey field on a ratio scale, i.e. prey size in relation to predator size (Ursin 1973). Pearre (1986) suggested that the width of prey size spectra, using a ratio scale, should be considered. He defined an index ('SLH') as the standard deviation of logarithmically transformed prey size data. In a review of the literature on predator/prey relationships, Pearre (1986) found no evidence for variation in the SLH index related to predator size.

The aim of the present study is to assess the applicability of the ratio scale in the description of preypredator relationships of herring larvae. Larval foraging and diet are investigated in order to: (1) evaluate the variation in larval search for prey and the size preference in relation to relative prey size, and (2) evaluate whether constraints in the ability to search and catch prey determine prey preference in the field.
Foraging behaviour of differently sized herring larvae were studied in a series of laboratory experiments, while information on prey preference in the field was obtained from a comparison between stomach contents of different size groups of larvae and the composition of zooplankton in the environment.

\section{MATERIALS AND METHODS}

Experiments. Four size groups of herring larvae Clupea harengus $\mathrm{L}$. were used in the experiments (see Table 1). Rearing of larvae took place in black, circular tanks of $600 \mathrm{l}$ capacity. In the rearing period, before onset of experiments, larvae were fed a mixed diet of copepods cultivated according to the technique described by Stattrup et al. (1986). In the experimental period, cohorts of uniformly sized Acartia tonsa and Calanus finmarchicus were raised. Experiments took place in black, circular tanks of $600 \mathrm{l}$ or $200 \mathrm{l}$ (the $200 \mathrm{I}$ only for the smallest size group of larvae), at a temperature of $10{ }^{\circ} \mathrm{C} \pm 0.5^{\circ} \mathrm{C}$, and salinity of $29 \%$. Tanks were lit by cool-white fluorescent light-tubes to $30 \mu \mathrm{mol} \mathrm{m}{ }^{-2} \mathrm{~s}^{-1}$ (ca 300 lux) at the surface.

Table 1. Clupea harengus. Experiments on the foraging of larval herring. Behavior of 4 size groups of larvae, observed at different sizes of prey (the copepods Acartia tonsa and Calanus finmarchicus). Values in brackets are calculated using swimming speed estimates as decribed in the text

\begin{tabular}{|c|c|c|c|c|c|c|c|c|}
\hline $\begin{array}{c}\text { Larval } \\
\text { length } \\
(\text { Mean } \pm S D) \\
(\mathrm{mm})\end{array}$ & $\begin{array}{l}\text { Copepod } \\
\text { length } \\
\text { (nominal) } \\
(\mathrm{mm})\end{array}$ & $\begin{array}{l}\text { Length } \\
\text { ratio } \\
\text { Cop./Larv. } \\
(\%)\end{array}$ & $\begin{array}{c}\text { Clearance based } \\
\text { on attacks (CA) } \\
(\text { Mean } \pm \mathrm{SD}) \\
\left(1 \mathrm{~min}^{-1}\right)\end{array}$ & $\begin{array}{l}\text { Attack } \\
\text { success } \\
\text { (AS) } \\
(\%)\end{array}$ & $\begin{array}{c}\text { Clearance }(\mathrm{C}) \\
(\text { Mean }) \\
\left(1 \mathrm{~min}^{-1}\right)\end{array}$ & $\begin{array}{l}\text { Swimming } \\
\text { speed (SS) } \\
\left(\mathrm{mm} \mathrm{s}^{-1}\right)\end{array}$ & $\begin{array}{c}\text { Curvature of } \\
\text { swimming } \\
\text { path } \\
\text { (\% deviation) }\end{array}$ & $\begin{array}{c}\text { Mean distance } \\
\text { of reaction } \\
\text { to attack } \\
(\mathrm{mm})\end{array}$ \\
\hline \multirow{7}{*}{$44.8 \pm 3.1$} & No prey & - & - & - & - & 170.2 & 9 & - \\
\hline & 0.1 & 0.22 & $0.17 \pm 0.05$ & - & 0.17 & 143.4 & 10 & 3.5 \\
\hline & 0.2 & 0.45 & $0.54 \pm 0.21$ & - & 0.54 & - & - & - \\
\hline & 0.4 & 0.89 & $2.3 \pm 0.68$ & - & 2.3 & 121.0 & 32 & 14.2 \\
\hline & 0.8 & 1.79 & $5.2 \pm 0.49$ & - & 5.2 & 89.6 & 29 & 24.8 \\
\hline & 1.5 & 3.35 & $17.3 \pm 8.2$ & 59 & 10.2 & 125.4 & 78 & 38.3 \\
\hline & 2.2 & 4.91 & $19.0 \pm 4.8$ & 50 & 9.5 & 138.9 & 49 & 38.1 \\
\hline \multirow{7}{*}{$33.5 \pm 2.8$} & No prey & - & - & - & - & 121.6 & 5 & - \\
\hline & 0.1 & 0.30 & $0.21 \pm 0.06$ & - & 0.21 & 144.1 & 5 & 3.9 \\
\hline & 0.2 & 0.60 & $0.48 \pm 0.10$ & - & 0.48 & 103.9 & 11 & 7.0 \\
\hline & 0.4 & 1.19 & $3.6 \pm 1.1$ & - & 3.6 & 60.3 & 20 & 25.2 \\
\hline & 0.8 & 2.39 & $4.8 \pm 1.1$ & - & 4.8 & 73.7 & 51 & 26.3 \\
\hline & 1.5 & 4.48 & $7.8 \pm 2.4$ & 49 & 3.8 & 73.7 & 41 & 33.5 \\
\hline & 2.2 & 6.57 & $9.4 \pm 0.7$ & 29 & 2.7 & 83.8 & 17 & 34.5 \\
\hline \multirow{5}{*}{$17.7 \pm 1.4$} & No prey & - & - & - & - & 19.5 & 16 & - \\
\hline & 0.1 & 0.57 & $0.05 \pm 0.007$ & - & 0.05 & 20.0 & 28 & 5.2 \\
\hline & 0.2 & 1.13 & $0.09 \pm 0.009$ & - & 0.09 & 14.0 & 22 & 8.3 \\
\hline & 0.4 & 2.23 & $0.12 \pm 0.014$ & 87 & 0.10 & 13.8 & 30 & 9.6 \\
\hline & 0.8 & 4.52 & $0.08 \pm 0.020$ & 43 & 0.03 & 14.9 & 21 & 7.5 \\
\hline \multirow{5}{*}{$13.5 \pm 1.4$} & 1.5 & 8.48 & $-\quad-$ & 0 & 0 & - & - & - \\
\hline & 0.1 & 0.74 & $0.015 \pm 0.003$ & 100 & 0.015 & - & - & $(3.3)$ \\
\hline & 0.2 & 1.48 & $0.041 \pm 0.008$ & 90 & 0.037 & - & - & (6.4) \\
\hline & 0.4 & 2.96 & $0.036 \pm 0.008$ & 78 & 0.028 & - & - & $(6.0)$ \\
\hline & 0.6 & 4.44 & $0.028 \pm 0.010$ & 34 & 0.010 & - & - & $\{5.1\}$ \\
\hline
\end{tabular}


The experimental procedure for a single experiment was as follows:

A given size group of larvae was offered a given size group of prey. This prey size was used in the feeding procedure for some days and, in order to attain a high level of hunger, it was ensured that the prey was grazed down about $18 \mathrm{~h}$ prior to onset of experiments. At the start of experiments, a given number of prey was added to the tank. The water was stirred gently and 5 to 10 samples of $5 \mathrm{l}$ each were taken from the upper water layer. Copepods were counted and the mean density estimated. The length of cephalothorax were measured on a subsample of 10 copepods.

Observations on larvae were initiated shortly after the prey sampling. Larval swimming behaviour was recorded using a video-camera mounted above the tank with focus $15 \mathrm{~cm}$ below water surface; whereas larval feeding behaviour was monitored by direct visual observation. Attack rate and duration were observed in 1 min sequences on randomly selected larvae in the tank. Attacks were identified as S-shaping of the body, followed by a burst forward. In some of the prey size/larval size combinations, the ingestion of prey could be followed and determination of attack success was possible. The number of attacks within each of 2 consecutive 5 min periods was registered. After these 2 periods, a final estimate of prey density was made. In later calculations (see below) the first $5 \mathrm{~min}$ period was related to the initial estimate of prey density, whereas the second period was related to the final density estimate.

The experimental procedure was repeated for all larval size/prey size combinations until about eight 5 min observations were obtained for each combination (only 4 when using Calanus finmarchicus).

The percentage of attacks that resulted in ingestion (attack success, AS) was estimated independently from a series of observations on attacking larvae. Success was evaluated either from an appearance of copepods in the translucent gut (for the 2 groups of smaller larvae) or from a disapperance of the attacked copepod (the 2 groups of larger larvae attacking the larger copepods).

Swimming speed (SS) was estimated by measuring larval movement from video-frame to video-frame $(1 / 25 \mathrm{~s}$ between each) of individual larvae in focus (Fig. 1). Distances were related to body length. The time spent in attack postures was not included in the estimation of mean swimming speed. A relative measure of the turning rate of larvae (the curvature of swimming path) was calculated as the length of a swimming path divided by the linear distance from start to end of path.

The intensity of larval search for prey is described by the imaginary volume of water the larvae are able

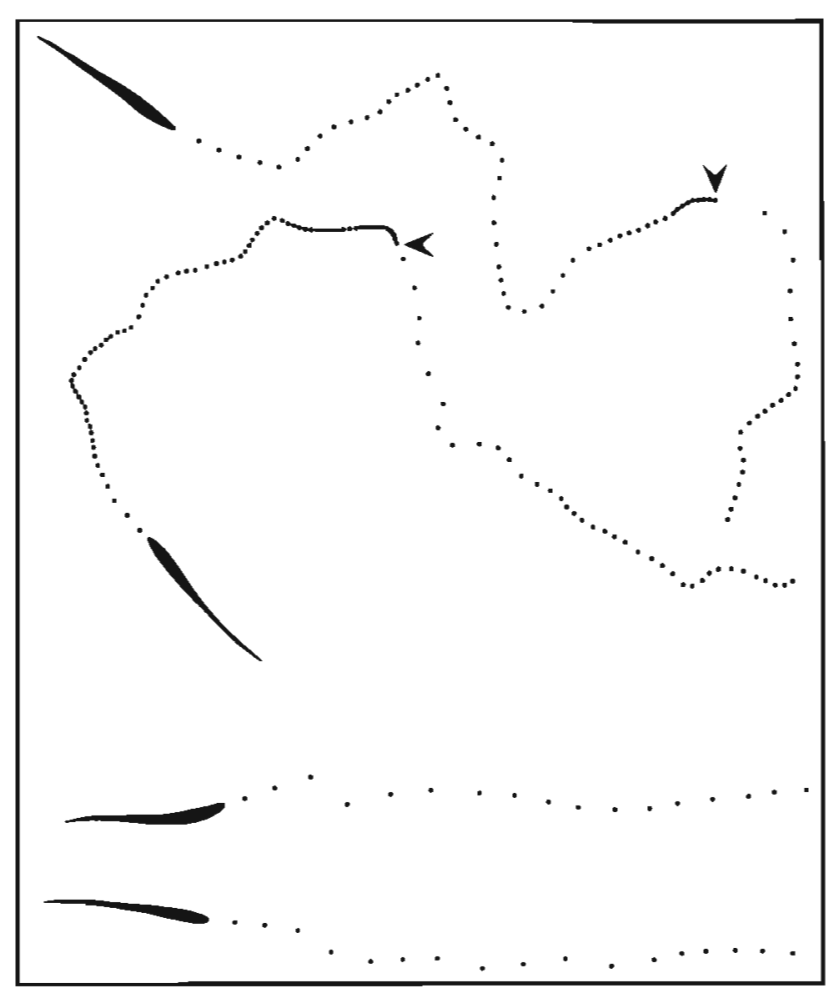

Fig. 1. Clupea harengus. Examples of swimming paths of larvae during experiments. Larvae from the $33.5 \mathrm{~mm}$ group are viewed from above, and the dots illustrate movement of their heads in $1 / 25 \mathrm{~s}$ steps. The 2 larvae with straight paths were experiencing a prey length of $100 \mu \mathrm{m}$, the other larvae a prey length of $800 \mu \mathrm{m}$. Arrows indicate onset of prey attacks

to 'clear' of prey within a certain time interval. A clearance (vol. time ${ }^{-1}$ ), comparable to clearance of filtering zooplankters (e.g. Frost 1972), was calculated. The procedure was to first calculate a clearance based on the observed attacks, and thereafter to calculate actual clearance by considering the independent estimate of attack success (AS), thus:

Clearance based on attacks $(\mathrm{CA})=[$ no. of attacks $] /$

[(obs. time - duration of attacks) $\times$ prey density] (1

$$
\text { Clearance }(\mathrm{C})=\mathrm{CA} \times \mathrm{AS} \text {. }
$$

The mean distance from the larva to prey that is ultimately attacked (with or without success) was assessed. Here it was assumed that only one prey item was potentially available at a time, and that larvae react only to prey above and in front of the head (Rosenthal \& Hempel 1970), thus:

Mean distance of reaction leading to attack $(\mathrm{MDR})=(2 \mathrm{CA} / \pi \mathrm{SS})^{1 / 2}$

where SS = swimming speed. 
Table 2. Clupea harengus. Field samples used in analysis of stomach content of larvae. Two length groups were separated at each station

\begin{tabular}{|c|c|c|c|c|}
\hline \multirow[t]{2}{*}{ Station } & \multirow[t]{2}{*}{ Sampling date } & \multirow[t]{2}{*}{ Sampling position } & \multicolumn{2}{|c|}{ Standard length of larval groups (mm } \\
\hline & & & $\begin{array}{l}\text { Preserved } \\
\text { Mean } \pm S D\end{array}$ & $\begin{array}{l}\text { Corrected }^{\mathrm{a}} \\
\text { Mean } \pm \mathrm{SD}\end{array}$ \\
\hline 1 & $1 \operatorname{Dec} 1987$ & $57^{\circ} 15^{\prime} \mathrm{N}, 0^{\circ} 00$ & $\begin{array}{l}14.0 \pm 1.0 \\
17.8 \pm 1.6\end{array}$ & $\begin{array}{l}17.5 \pm 1.3 \\
22.3 \pm 2.0\end{array}$ \\
\hline 2 & 4 Dec 1987 & $58^{\circ} 15^{\prime} \mathrm{N}, 0^{\circ} 30^{\prime} \mathrm{E}$ & $\begin{array}{l}18.5 \pm 0.5 \\
20.8 \pm 0.6\end{array}$ & $\begin{array}{l}23.1 \pm 0.9 \\
26.0 \pm 0.8\end{array}$ \\
\hline 3 & 3 Mar 1988 & $55^{\circ} 15^{\prime} \mathrm{N}, 5^{\circ} 30^{\prime} \mathrm{E}$ & $\begin{array}{l}24.3 \pm 0.9 \\
29.4 \pm 1.3\end{array}$ & $\begin{array}{l}30.4 \pm 1.1 \\
36.8 \pm 1.6\end{array}$ \\
\hline
\end{tabular}

Field material. Sampling of larvae and their potential prey took place during 2 cruises in the North Sea in November 1987 and February 1988. Three stations were selected for detailed analysis of prey size spectra (Table 2), Larvae were sampled in late afternoon using a fine meshed midwater trawl and preserved in $4 \%$ formalin. Later, larval guts were dissected and copepod cephalothorax remains identified. Standard length of larvae and cephalothorax length of copepods were measured using an ocular micrometer (within $1 / 10$ and $1 / 100 \mathrm{~mm}$ respectively). Lengths of larvae were calibrated to live length using an estimated shrinkage of $20 \%$ (Blaxter 1971).

Field samples of copepods were collected by a submersible pump which pumped into a net of $30 \mu \mathrm{m}$ mesh size. Flow rate was $0.5 \mathrm{~m} \mathrm{~s}^{-1}$ at the net opening of $0.1 \mathrm{~m}^{2}$. Samples were depth-integrated by lowering the pump slowly through the water column and about $17 \mathrm{~m}^{3}$ were pumped at each station. Samples were preserved in $4 \%$ formalin and later zooplankters in subsamples were identified and the cephalothorax length of copepods measured (within $20 \mu \mathrm{m}$ intervals).

An index of prey preference $(\alpha)$ was calculated (Chesson 1978):

$$
\alpha_{j}=\left(d_{j} / p_{j}\right) /\left(\sum d_{i} / p_{i}\right), \text { for } i=1 \ldots, n
$$

where $d_{j}=$ the portion, in terms of numbers, of prey size $j$ in the gut; $p_{j}=$ the portion of prey size $j$ in the environment.

\section{RESULTS}

\section{Larval foraging during experiments}

All groups of larvae continuously swam/searched during experiments. However, the swimming mode differed between smaller and larger larvae. While the former swam in the undulating mode described by
Rosenthal (1968), the latter 'cruised' with less prominent undulation of the body. The swimming speeds of 3 of the larval groups are shown in Table 1 and Fig. 2a. Over the range of prey size combinations, the swimming speed in body lengths per second (BL $\mathrm{s}^{-1}$ ) generally increased with larval size. The mean of swimming speeds at prey/larval length ratios larger than 0.007 showed a linear relationship on an absolute scale: Swimming speed $\left(\mathrm{mm} \mathrm{s}^{-1}\right)=-54.5+3.8$ larval length $(\mathrm{mm}), \mathrm{r}^{2}=0.99, \mathrm{n}=3$. Swimming speed was also related to prey size, showing a minimum at a preylarval length ratio of about 0.015 . This variation was correlated to variation in attack rate $(p<0.002)$, which indicated that the effect stems from the interruption of swimming while larvae attack prey.

Mode of larval swimming differed between experiments. When prey was absent or of a very small relative size, larvae followed a fairly straight swimming path. At larger relative prey sizes, however, more curved paths were followed (see examples in Fig. 1). The degree of curvature is here expressed as the percent extra distance compared to the straight route (Table 1 and Fig. 2b). Larvae showed the most curved swimming path when prey length was about 0.025 of larval length. This behavioural characteristic was not related to attack rate $(p>0.6)$, but was correlated to mean distance of reaction, MDR ( $p<0.03)$.

Clearances estimated from Eq. (2) are shown in Table 1 and Fig. 3. In experiments where no estimate of attack success was available, $100 \%$ success was assumed. The clearance of all size groups of larvae increased with prey size until a given prey size and subsequently declined. Maximum was about 0.041 $\mathrm{min}^{-1}$ for the smallest larvae, and about $101 \mathrm{~min}^{-1}$ for the largest larvae. The prey size at which maximal clearance was attained (here referred to as optimal prey size) increased with larval size. In a regression of optimal prey lengths against larval lengths, the intercept was not different from zero $(p>0.17)$ and the following relationship was attained: Optimal prey 

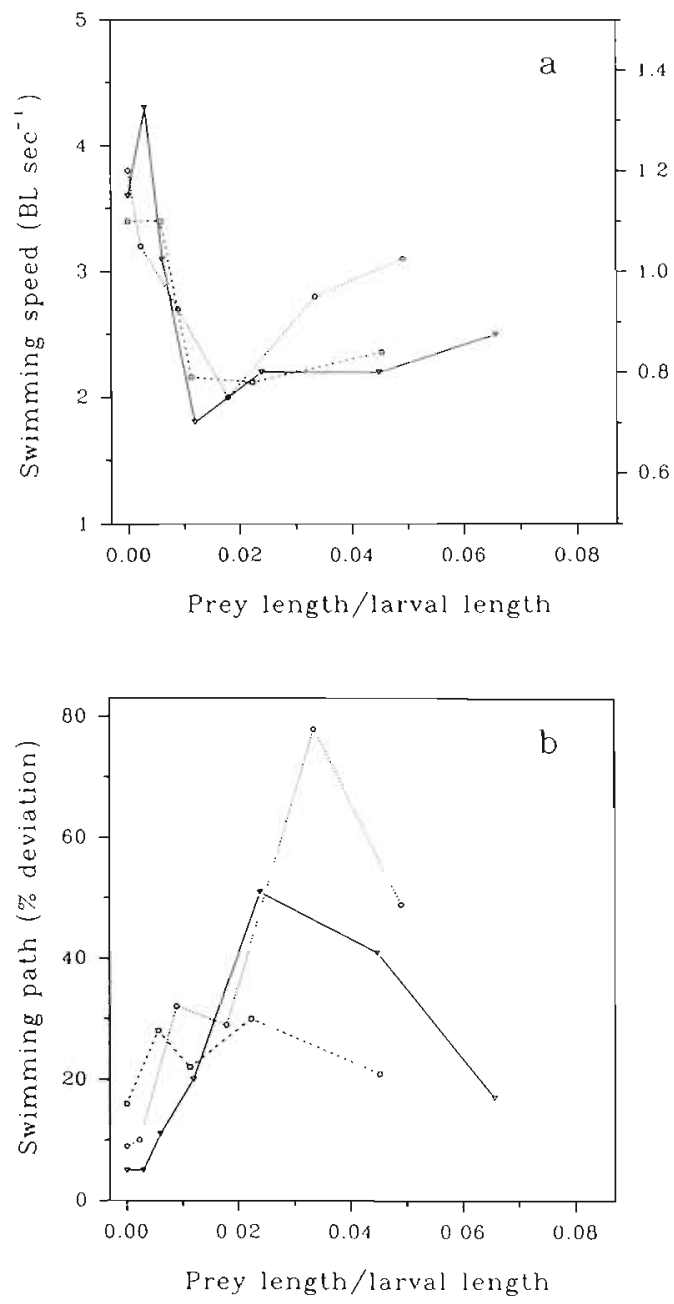

Fig. 2. Clupea harengus. Swimming behaviour of larvae during experiments. (a) Variation in swimming speed (body lengths per second), observed at different ratios of prey to larval length. Left axis refers to the $44.8 \mathrm{~mm}$ group $(0 \cdots \cdots$.$) and$ the $33.5 \mathrm{~mm}$ group $(\square \longrightarrow$ ). Right axis refers to the $17.7 \mathrm{~mm}$ group (a----c). (b) Variation in curvature of the swimming path, measured as the extra distance compared to the straight path observed at different ratios of prey to larval length. Symbols as in (a)

length (mm, cephalothorax length of copepods) $=0.028$ larval length ( $\mathrm{mm}$, live standard length), $\mathrm{r}^{2}=0.97, \mathrm{n}=4$.

Estimates of clearances are based on the assumption that, while larvae are hungry, feeding rate will be linearly related to prey density (i.e. that estimates of clearances are independent of prey density). The validity of this assumption was investigated in a covariance test of the prey density effect on clearance in 11 prey/larval length combinations. The effect of the density was insignificant $(p>0.79)$.

The mean distance of reaction leading to attack was calculated using Eq. (3). In Table 1, distances are given in mm. In Fig. 4, they are shown in units of body lengths against the prey/larval length ratio. In

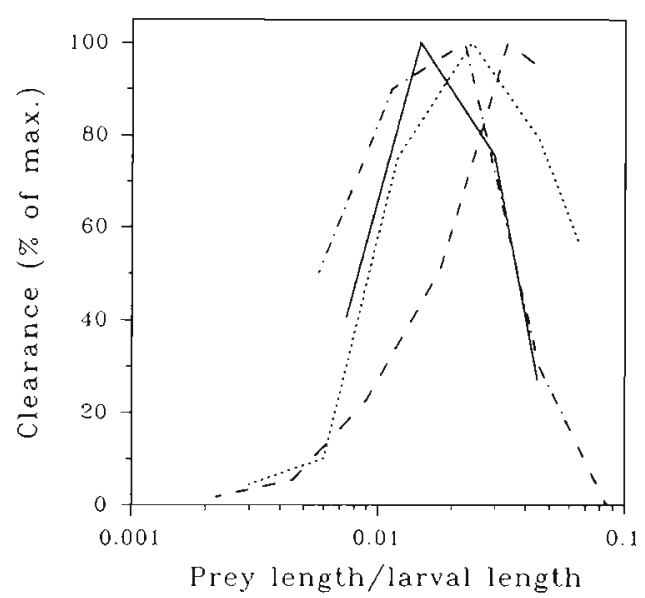

Fig. 3. Clupea harengus. Relative clearance estimates ( $\%$ of maximum clearance) for larvae during experiments. Variation in relative clearance as a function of the ratio of prey length to larval length. Line types refer to larval size groups: $44.8 \mathrm{~mm}$ $(---), 33.5 \mathrm{~mm}(\cdots), 17.7 \mathrm{~mm}(-\cdot-\cdot-)$ and $13.5 \mathrm{~mm} \mathrm{(-)}$

the figure, values from either the 2 smaller-sized or the 2 larger-sized groups are connected by eye-fitted lines. At the smallest relative prey sizes (relative size $<0.017$ ), the mean distances of reaction showed approximately the same relationship to relative prey size for all larval size groups; above this size, groups showed different relationships and these deviated from linearity. While a reactive distance based on perception is expected to increase linearity with prey size (Schmidt \& O'Brien 1982), the observations illustrate that a decreasing percentage of the perceived

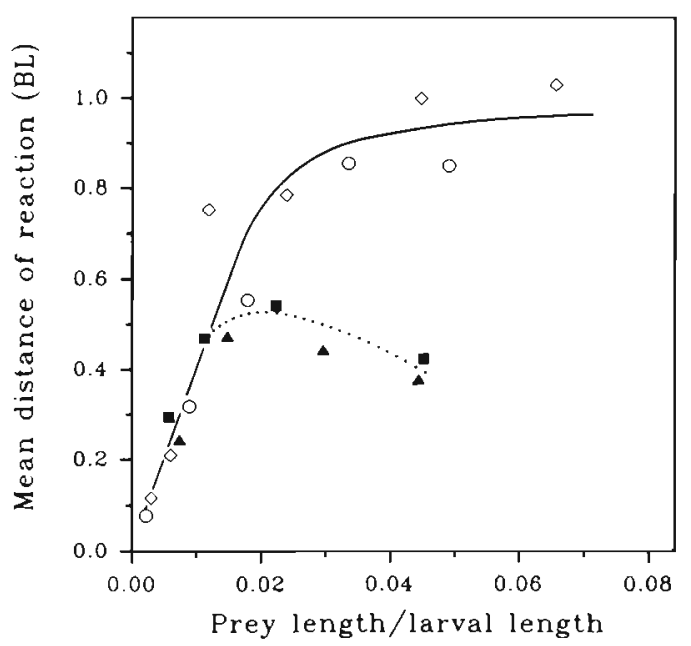

Fig. 4. Clupea harengus. Mean reaction distance of larvae estimated at different ratios of prey to larval length. Symbols refer to larval size groups: $44.8 \mathrm{~mm}(0), 33.5 \mathrm{~mm}(\diamond), 17.7 \mathrm{~mm}$ (-) and $13.5 \mathrm{~mm}(\mathbf{4})$. Values for the 2 larger-sized groups (open symbols) and for the 2 smaller-sized groups (filled symbols) are connected by eye-fitted lines 
prey were attacked. In the experiments with the 2 smaller-sized larval groups, the deviation is seen at a prey/larval length ratio smaller than for the 2 largersized groups. This is consistent with unquantified observations made of attack postures that do not lead to an attack. The smaller larvae frequently gave up a perceived (and approached) prey, whereas this was seldomly observed in the larger sized groups. The larger larvae in some cases attacked the same prey several times, a behaviour never seen in the experiments with smaller larvae.

Attack success declined when the relative prey size increased (Table 1, Fig. 5). The relationship is described by a linear regression for all observations: Attack success $=1.1-13.6$ (prey length/larval length), $\mathrm{r}^{2}=0.82, \mathrm{n}=11$.

\section{Field observations}

The size distributions of the copepods found in larval guts are shown for 6 size groups of larvae in Fig. 6 a to $f$. Logarithmic length intervals are used. Each size distribution accumulates to $100 \%$ and is based on about 50 prey items. In Fig. $6 g$ to $i$, the measured densities and biomass of copepods are shown within the same intervals. At all 3 stations, the density of copepods declined with increase in size. Consequently, the distributions of prey size preference (Eq. 4) also shown in Fig. 6a to f are shifted to the right compared to the size distribution of gut contents. Both mean length of preferred prey (optimal prey length) and mean length of prey in gut are linearly related to larval length (Fig. 7). The intercept in a regression of

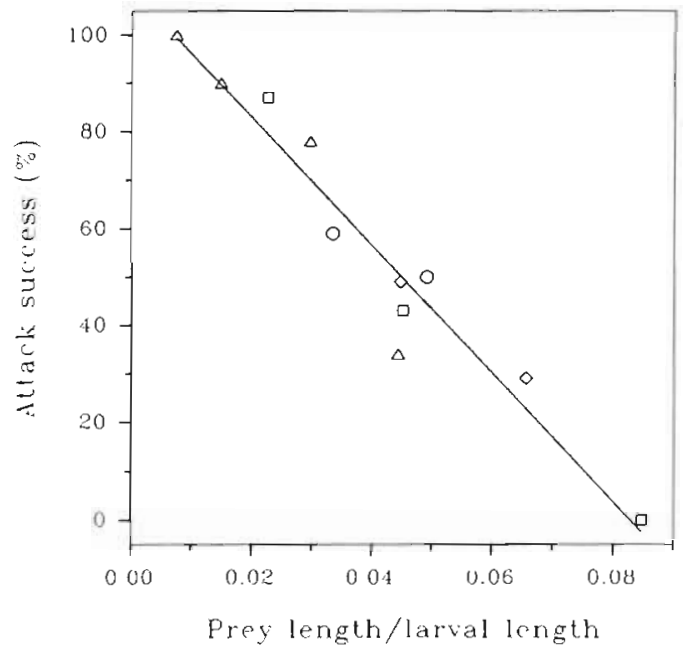

Fig. 5. Clupea harengus. Success of attacks by larvae in experiments. Variation in the percentage of attacks that leads to consumption, shown against relative prey size. Symbols refer to larval size groups: $44.8 \mathrm{~mm}(0), 33.5 \mathrm{~mm}(\diamond), 17.7 \mathrm{~mm}$ (a) and $13.5 \mathrm{~mm}(\Delta)$. A linear regression for all data is shown optimal prey size against larval size did not differ significantly from zero $(p>0.6)$, and a regression forced through the origin reveals: Prey length (mm, cephalothorax length $)=0.027$ larval length $(\mathrm{mm}$, standard converted to live length).

Accordingly, when preference is scaled as percentage of the maximal preference, the heights of size spectra fall together on the scale of prey/larval length ratios (Fig. 8). The width of prey size spectra, expressed as the standard deviation of log-transformed prey size data (SLH index), was not significantly related to larval size. The SLH indices are, when using gut content or prey preference, 0.118 and 0.102 , respectively.

\section{DISCUSSION}

The observations on larval foraging behaviour showed that the functional relationship between search rate and relative prey size was mainly determined by 4 components of larval behaviour: (1) perception distance, (2) the probability that perception led to attack, (3) the probability of successful attack, and (4) the swimming speed.

The estimated distance of reaction leading to an attack emphasizes both the recognition of a prey item and the probability that this will be attacked. Data from an earlier study (Munk \& Kiørboe 1985) showed that from 40 to $90 \%$ of perceptions are followed by an attack, and the smaller the relative prey size the larger the probability of attack. The variation in the probability is also evident from the observed changes in the distance of reaction to attack (Fig. 4). The differences between larval groups might be related to enhanced visual acuity and enhanced larval manoeuverability.

Attack success was directly related to relative prey size, irrespective of larval size. Attack success approached zero at relative prey sizes of 0.08 , and thereby determined an upper limit of effective search. Rosenthal (1969) found a direct relationship between attack success, age and length in experiments using prey of the same size. This is consistent with the direct relationship to relative prey size described here. The probabilities of success are similar to the values given in an earlier study (Kiørboe \& Munk 1986) when compared at the same relative prey sizes.

Swimming speed is important in determining the attainable search rate and to a large extent responsible for the higher absolute search rate of the larger larvae (at a given prey size). The observed decline in swimming speed with increased prey size was related to differences in attack rates. The more attacks, the slower the speed. This influence probably stems from the disruption of continued swimming while per- 

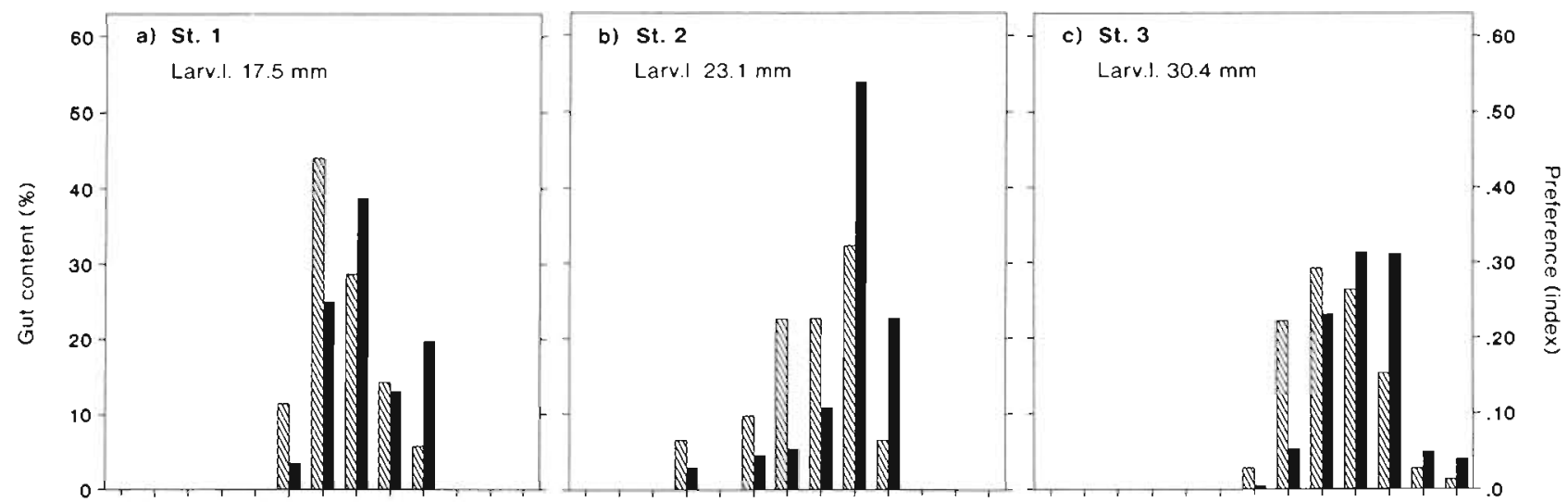

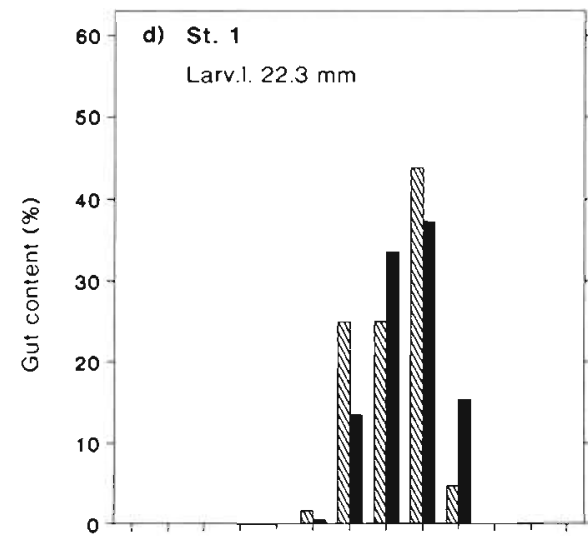

e) St. 2 Larv.l. $26.0 \mathrm{~mm}$
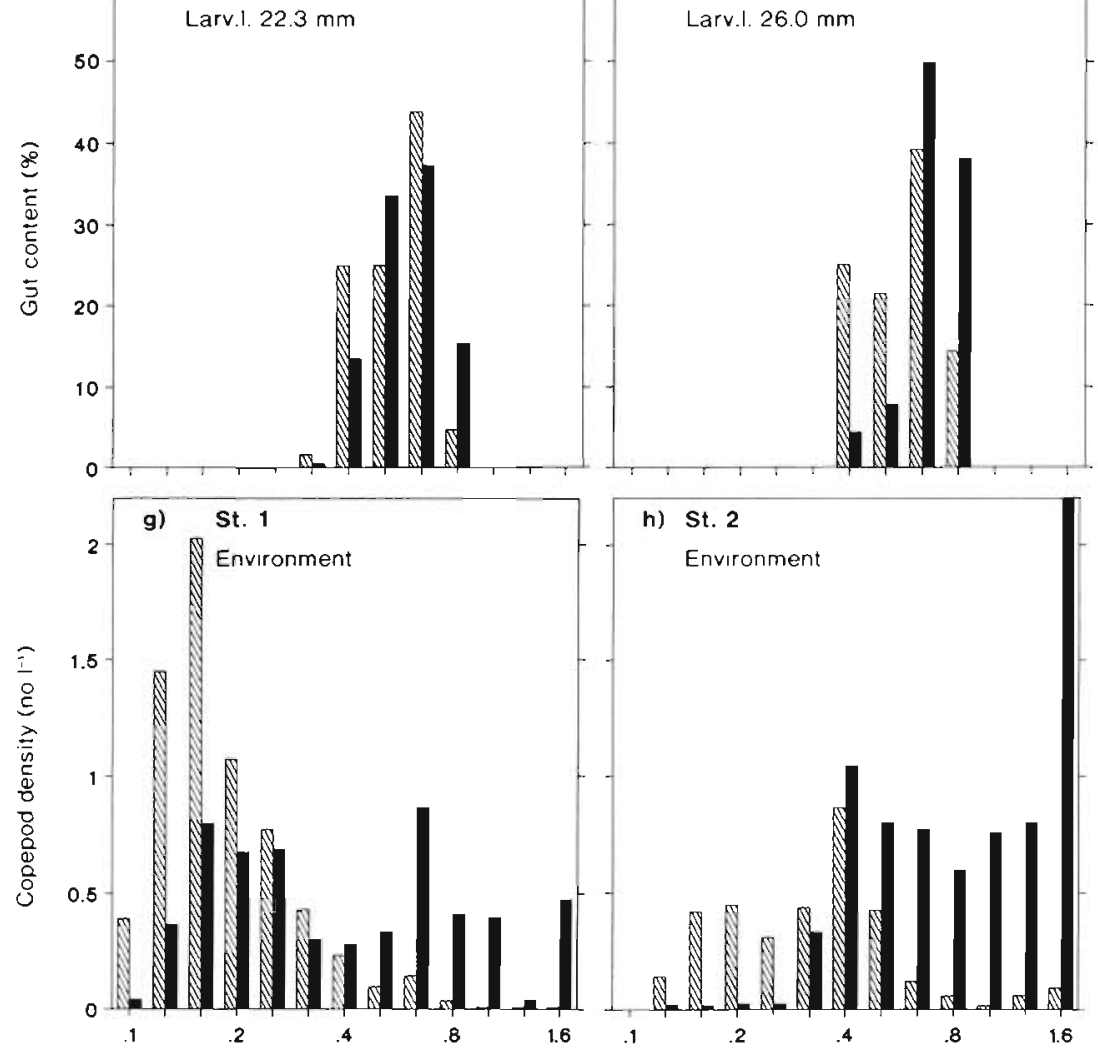

h) St. 2 Environment

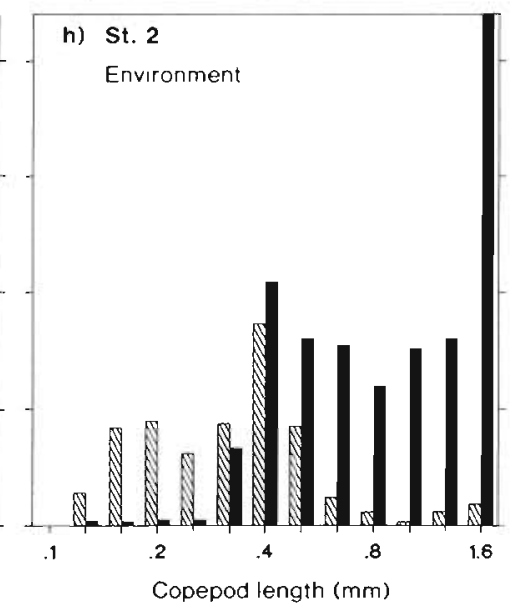

f) St. 3

Larv.I. $36.8 \mathrm{~mm}$
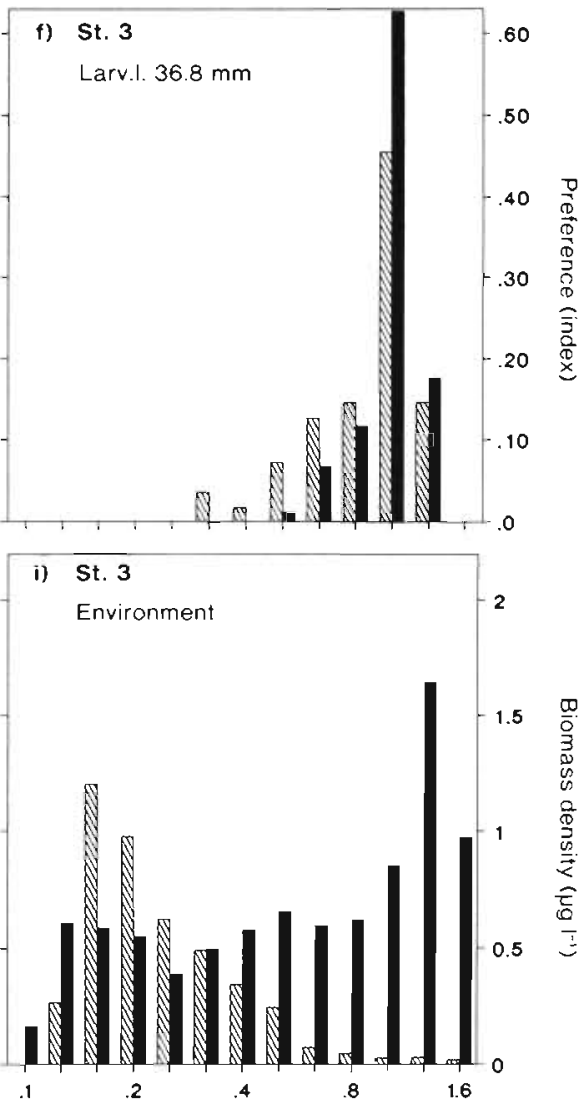

Fig. 6. Field sampling of larval herring Clupea harengus and copepods. All bars in figures represent logarithmic intervals of copepod lengths (midpoints at tickmarks). (a) to (f) Relative amount of copepods in guts of larvae, illustrated by shaded bars read on the left axis; preference of copepod length illustrated by solid bars read on the right axis. Each figure represents data for 1 size group of larvae sampled at 1 station (Table 2); larv.1 = mean length of larvae. (g) to (i) Density of copepods (no. $1^{-1}$ ) shown as shaded bars read at the left axis; biomass density of copepods $\left(\mu \mathrm{g}^{-1}\right)$ shown as solid bars read at the right axis. Each figure represents data for a given station (Table 2)

forming an attack, and a slower speed used while approaching prey. On the other hand, the curvature of the swimming path was related to distance of attack-reaction to prey. Thus, this component of larval foraging behaviour is influenced by size of prey.
In interpreting the influence of relative prey size the variation in size is assumed to take place isometrically. However, the morphology of both larvae and prey varied within the size range used. For example, increase in length of herring larvae is accompanied by a change in relative mouth size, fin devel- 


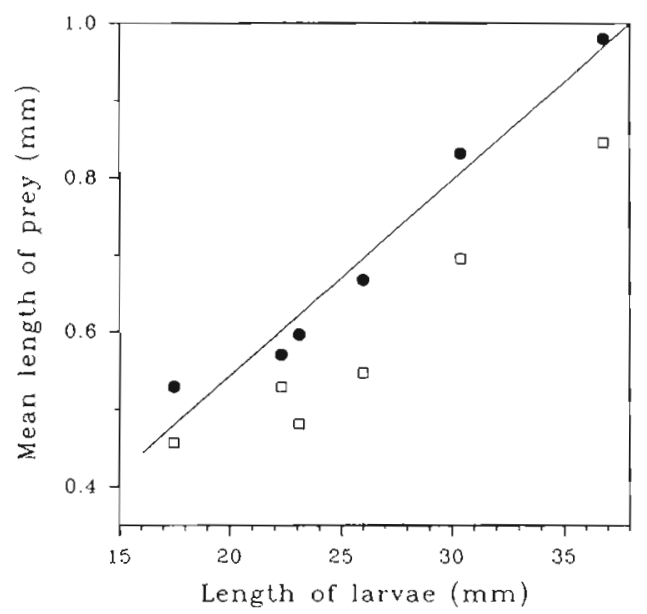

Fig. 7. Clupea harengus. Mean and optimum prey size of larvae as observed from field sampling. Mean length of copepods in the gut $(0, \ldots \ldots \ldots)$ and copepod size of maximum preference indices $(\bullet,-)$ are shown against mean length of larvae in groups

opment and body depth, whereas the copepods are in different stages (nauplii, copepodites). Prey characteristics related to stage or species of prey, such as contrast and escape ability, have been shown to influence predator behaviour in a number of cases (e.g. Kislalioglu \& Gibson 1976, Drenner et al. 1978, Checkley 1982).

Thus, variation in morphological characteristics, along with the variation in length of larvae and prey, is expected to influence the relationship between foraging capability and relative prey size. However, the similarities among the relationships of clearance versus relative prey size determined for the 4 larval size groups (Fig. 3) indicate that relative prey size is of prime importance in determining larval foraging during experiments: first, the major restrictions to larval clearance - the decrease in reaction distance at the smaller relative sizes of prey and the decrease in attack success at the larger relative prey sizes - were not related to larval mean size in the given range of relative prey sizes; second, maximal clearance of each size group was found at approximately the same relative prey size.

The prey size spectra of preference in the field describe relative consumption (i.e. successful attacks) calibrated for differences in prey density. Thus, like the experimentally determined variation in clearance, these spectra express the intensity of successful search for prey along an axis of relative prey sizes. The major (and important) difference between the 2 is that the field material is based on larval search in mixed prey assemblages, where selection between different prey sizes is possible.

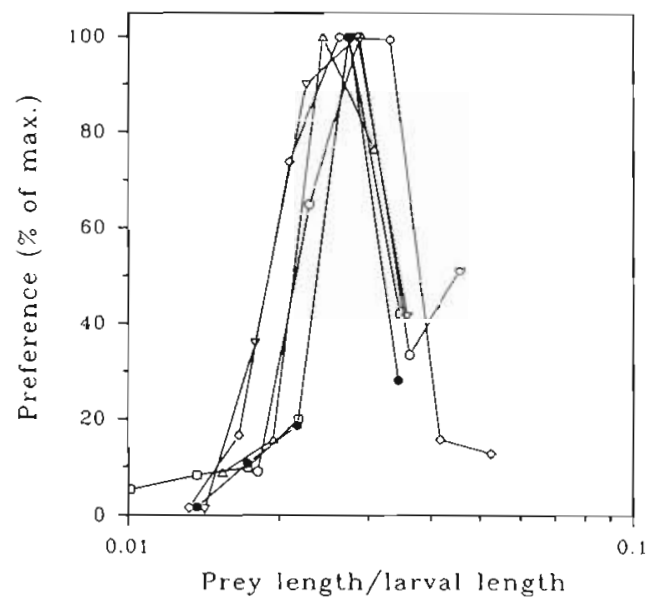

Fig. 8. Clupea harengus. Prey size spectra of larvae in the field. Spectra of preference for relative prey size shown on a logarithmic scale. Maximal preference equals $100 \%$ in each spectrum. Symbols indicate larval groups: $36.8 \mathrm{~mm}(0)$, $30.4 \mathrm{~mm}(\nabla), 26.0 \mathrm{~mm}(\square), 23.1 \mathrm{~mm}(\Delta), 22.3 \mathrm{~mm}(\diamond)$ and $17.5 \mathrm{~mm}(\bullet)$

When comparing the relative prey size spectra from the laboratory and the field (Figs. $3 \& 8$ ), both similarities and differences are evident. In both cases, the distributions approximate a log-normal distribution, and their width and maxima are independent of larval size. Characteristics of larval behaviour determining optimal prey size in the experiments are apparently valid for the field as well, because both sets of distributions (experimental and field) have their maxima within the same narrow range of relative prey sizes $(0.025$ to 0.030$)$. On the other hand, the width of the distributions from the experiments are much larger than the width determined from field material. Expressed in terms of SLH index, the experimentally determined distributions are about 3 times as wide as those from the field. This narrowing of prey size spectra from the field suggests a strong selection for the optimal prey size, with larvae excluding the smallest and the largest prey sizes which they are capable of eating.

It is possible that the smallest fraction was missed in the present analysis of stomach contents. In comparable studies of the diet of herring larvae, prey items smaller than $200 \mu \mathrm{m}$ were found in the gut (Sherman \& Honey 1971). A failure to represent the lower tail of the distribution properly has some influence on the calculation of the SLH index and could explain the difference between the present calculations and the values given by Pearre (1986). Such a bias would not, however, influence the main conclusion, that the ratio between sizes of prey and larvae to a large extent determines relative availability of prey, irrespective of larval size. 
The possibility that larger larvae could use the prey items available to smaller larvae, plus additional larger prey items, has fostered the impression that the available food resource increases as larvae grow. An 'efficiency of size' has been hypothesized (Brooks \& Dodson 1965). However, uniformity of relative prey size spectra, as illustrated in the present study, implies that. a priori, the available biomass of food (as proportion of predator biomass) will not increase.

Changes in prey availability during larval growth depend to a large extent on the distribution of zooplankton biomass by size. Sheldon et al. (1972) investigated the distribution of biomass by particle size and defined a biomass spectrum by the accumulated biomass within logarithmic intervals of size. He proposed that, within logarithmic intervals, essentially the same biomass is found. However, significant variations in biomass spectra are observed on regional and seasonal scales, as exemplified by the measurements in the present study (Fig. $6 \mathrm{~g}$ to i). The biomass of copepods, the dominant zooplankton prey of herring larvae, peaks within certain intervals and the trends are different between stations. Hence, coincidence between prey size spectra of larvae and peaks in biomass spectra are potentially of great importance to larval growth and survival. The match between larvae and prey is the basis of much debated hypotheses, the 'critical period' concept of Hjort (1914) and the 'matchmismatch' hypotheses of Cushing (1975). While these hypotheses direct attention to prey-larvae interactions in the very early stages, the present findings indicate that the match between larvae and an abundance of prey of appropriate size is of continued importance throughout larval life.

\section{LITERATURE CITED}

Bence, J. R., Murdoch, W. W. (1986). Prey size selection by the mosquito fish: relation to optimal diet theory. Ecology 67: 324-336

Blaxter, J. H. S. (1971). Feeding and condition of Clyde herring larvae. Rapp. P.-v. Réun. Cons. int. Explor. Mer 160: $128-136$

Brooks, J. L., Dodson, S. I. (1965). Predation, body size, and composition of plankton. Science 150: 28-35

Checkley, D. M. Jr (1982). Selective feeding by Atlantic herring (Clupea harengus) larvae on zooplankton in natural assemblages. Mar. Ecol. Prog. Ser. 9: 245-253

Chesson, J. (1978). Measuring preference in selective predation. Ecology 59: 211-215

Cohen, R. E., Lough, R. G. (1983). Prey field of larval herring Clupea harengus on a continental shelf spawning area. Mar. Ecol. Prog. Ser. 10: 211-222

Cushing, D. H. (1975). Marine ecology and fisheries. Cambridge University Press, London
Drenner, R. W., Strickler, J. R., O'Brien, W. J. (1978). Capture probability: the role of zooplankter escape in the selective feeding of planktivorous fish. J. Fish. Res. Bd Can. 35 : $1370-1373$

Frank, K. T. (1988). Independent distributions of fish larvae and their prey-paradox or sampling artifact? Can. J. Fish. Aquat. Sci. 45: 48-59

Frost, B. W. (1972). Effects of size and concentration of food particles on the feeding behaviour of the marine planktonic copepod Calanus pacificus. Limnol. Oceanogr. 17(6): $805-815$

Hjort, J. (1914). Fluctuations in the great fisheries of Northern Europe viewed in the light of biological research. Rapp. P.-v. Réun. Cons. int. Explor. Mer 20: 1-128

Jones, C. (1985). Within-season differences in growth of larval Atlantic herring, Clupea harengus. Fish. Bull. U.S. 83: 289-298

Kislalioglu, M., Gibson, R. N. (1976). Some factors governing prey selection by the 15-spined stickleback, (Spinachia spinachia L.). J. exp. mar. Biol. Ecol. 25: 159-169

Kiorboe, T., Munk, P. (1986). Feeding and growth of larval herring, Clupea harengus, in relation to density of copepod nauplii. Environ. Biol. Fish. 17: 133-139

Munk, P., Heath, M., Skaarup, B. (1991). Regional and seasonal differences in growth of larval North Sea herring (Clupea harengus L.) estimated by otolith microstructure analysis. Cont. Shelf Res. 11(7): 641-654

Munk, P., Kiorboe, T. (1985). Feeding behaviour and swimming activity of larval herring (Clupea harengus) in relation to density of copepod nauplii. Mar Ecol. Prog. Ser. 24: $15-21$

O'Brien, W. J., Slade, N. A., Vinyard, G. L. (1976). Apparent size as the determinant of prey selection by bluegill sunfish (Lepomis macrochirus). Ecology 57: 1304-1310

Pearre, S. Jr (1986). Ratio-based trophic niche breadths of fish, the Sheldon spectrum, and the size-efficiency hypothesis. Mar. Ecol. Prog. Ser. 27: 299-314

Pyke, G. H., Pulliam, H. R., Charnov, E. L. (1977). Optimal foraging: a selective review of theory and tests. $Q$. Rev. Biol. 52: $137-154$

Rosenthal, H. (1969). Untersuchungen über das Beutefangverhalten bei Larven des Herings Clupea harengus. Mar. Biol. 3: 208-221

Rosenthal, H. (1968). Schwimmverhalten und Schwimmgeschwindigheit bei den Larven des Herings Clupea harengus. Helgoländer wiss. Meeresunters. 18: 453-486

Rosenthal, H., Hempel, G. (1970). Experimental studies in feeding and food requirements of herring larvae (Clupea harengus L.). In: Steele, J. H. (ed.) Marine food chains. Univ. of California Press, Berkeley, p. 344-364

Schmidt, D., O'Brien, W. J. (1982). Planktivorous feeding ecology of Arctic grayling (Thymallus articus). Can. J. Fish. Aquat. Sci. 39: 475-482

Schoener, T W. (1971). Theory of feeding strategies. Ann. Rev. Ecol. Syst. 2: 369-404

Sheldon, R. W., Prakash, A., Sutcliffe, W. H. Jr (1972). The size distribution of particles in the ocean. Limnol. Oceanogr. 17: $327-340$

Sherman, K., Honey, K. A. (1971). Seasonal variation in the food of larval herring in the coastal waters of central Maine. Rapp. P.-v. Réun. Cons. int. Explor. Mer 160: $121-124$

Støttrup, J. G., Richardson, K., Kirkegaard, E., Pihl, N. J. (1986). The cultivation of Acartia tonsa Dana for use as a live food source for marine fish larvae. Aquaculture 52: $87-96$ 
Suthers, I. M., Frank, K. T., Campana, S. E. (1989). Spatial comparison of recent growth in postlarval Atlantic cod (Gadus morhua) off southwestern Nova Scotia: inferior growth in a presumed nursery area. Can. J. Fish. Aquat. Sci. 46: 113-124

Ursin, E. (1973). On the prey size preference of cod and dab Meddr. Danm. Fisk. og Havunders. N.S. 7: 85-98

This article was presented by T. Kiorboe, Charlottenlund, Denmark
Ware, D. M. (1972). Predation by rainbow trout (Salmo gairdneri): the influence of hunger, prey density and prey size J. Fish. Res. Bd Can. 29: 1193-1201

Wetterer, J. K., Bishop, C. J. (1985). Planktivore prey selection: the reactive field volume model vs. the apparent size model. Ecology 66: $457-464$

Manuscript first received: October 18, 1991

Revised version accepted: January 30, 1992 